\title{
Thomas Hobbes e a controvérsia acerca da interpretação da lei: uma questão jurídica contemporânea vista à luz do Commonwealth hobbesiano
}

\author{
Wladimir Barreto Lisboa \\ Unisinos \\ wlisboa@via-rs.net
}

resumo 0 objetivo desse artigo é mostrar de que modo um problema no domínio da teoria contemporânea do direito suscita questões que podem encontrar esclarecimentos na filosofia de Thomas Hobbes. Para tanto, será primeiramente analisada uma decisão da Suprema Corte norte-americana que retoma um debate constitucional aberto há já quase vinte anos e que versa sobre os direitos civis ${ }^{1}$. Nesse contexto, a noção de República em Hobbes será apresentada enquanto fornecendo uma teoria sobre a interpretação jurídica que permite apanhar o bom lado nesse debate.

palavras-chave Thomas Hobbes, filosofia política, república, direitos civis.

\section{0 caso Lawrence et alli versus Texas: premissa majoritária e leitura moral da constituição.}

Convém lembrar, de início, os elementos factuais e o processo judicial que estão na origem da decisão da Suprema Corte norte-americana no caso Lawrence. Chamados por suposta perturbação de sossego, policiais de Houston penetram no domicílio de Lawrence e o surpreendem mantendo relações sexuais com outro homem. Os dois indivíduos são presos preventivamente e posteriormente condenados pela lei do Texas que reprime a prática da sodomia entre duas pessoas do mesmo sexo. Após a rejeição do recurso em apelação, os dois denunciados dirigem-se à Suprema Corte. A decisão é de 26 de junho de 2003. A Corte, na ocasião, põe diante de si três questões a serem decididas ${ }^{2}$. 1) "Se a condenação dos recorrentes 
segundo a lei do Texas que criminaliza a prática sexual por adultos do mesmo sexo viola a décima quarta emenda que garante a igual proteção das leis [equal protection of laws]"3;2) "se a condenação dos recorrentes por terem mantido relações sexuais privadas e consentidas viola seu interesse vital à liberdade e à vida privada protegidos pelo processo legal regular [due process clause] da décima quarta emenda" 43 ) "se o precedente do caso Bowers v. Hardwick, 478 U.S. 186 (1986) deve ser revisado"5.

A Suprema Corte justificará sua mudança de posição no caso Lawrence a partir de uma interpretação da décima quarta emenda em virtude da qual nenhum Estado poderá privar uma pessoa de sua liberdade sem o processo legal regular [due process clause], nem recusar a todos que se encontram sob sua jurisdição a igual proteção das leis [equal protection of laws].

O Justice Kennedy, que redigiu o voto majoritário da Corte, afirmou que o ponto da questão consiste em saber se a maioria [isso é, o poder legislativo] pode utilizar seu poder de Estado para impor uma convicção moral a toda sociedade através da lei penal. "Nossa obrigação aqui [afirma o Justice Kennedy, citando Planned Parenthood of Southeastern Pa. v. Casey, 505 U.S. 833, 850 (1992)], consiste em definir a liberdade tout court, e não em fazer valer nosso código moral particular"6. Se aqueles que escreveram e ratificaram o artigo do due process da quinta emenda ou da décima quarta, continua o argumento, houvessem conhecido os componentes da liberdade em suas múltiplas possibilidades, eles teriam podido ser mais específicos. Eles sabiam não possuir esse insight. Eles sabiam que os tempos podem tornar-nos cegos a certas verdades que gerações futuras podem ver, e que leis um dia pensadas necessárias e adequadas não servem, na realidade, senão para oprimir. Como assegura a Constituição, o povo, em todas as gerações, pode invocar os princípios em sua própria busca de mais liberdade 7 .

O caso Lawrence coloca, desse modo, a questão acerca da existência, no centro desse "processo legal regular", de um direito à vida privada, no sentido de intimidade da vida sexual, que poderia ser reivindicado pelos homossexuais.

Pela maioria de seis votos contra três, o direito constitucional ao respeito à vida privada, incluindo a intimidade sexual, foi reconhecido aos homossexuais adultos engajados em uma relação livremente consentida. 
O Justice Scalia, autor de um dos votos minoritário da Corte, recusouse a reconhecer à Suprema Corte o poder de intervir e tomar posição em questões que sacodem a sociedade americana e sobre as quais os estados federados não estão de acordo. Fosse verdadeira a afirmação do Justice Stevens, voto minoritário no caso Bowers, segundo a qual o fato de que exista uma maioria governante em um estado que tradicionalmente tomou a prática homossexual imoral não é razão suficiente para aprovar uma lei que interditasse essa mesma prática, então, nessas circunstâncias, a regra da maioria estaria suspensa. Ora, se o estado não pode mais, por maioria, legislar em matéria moral, por conseqüência toda legislação incriminando a fornicação, a bigamia, o adultério, o incesto, a bestialidade, etc., seria ab-rogada. "The law, it said [no caso Bowers], is constantly based on notions of morality, and if all laws representing essentially moral choices are to be invalidated under the Due Process Clause, the courts will be very busy indeed. 478 U.S., at 196.” Mais do que tomar posição no debate moral, deveria a Corte, de modo imparcial, assegurar e observar que as regras democráticas da maioria sejam observadas. Que os homossexuais busquem persuadir os cidadãos de que seu modo de vida é o melhor, prossegue Justice Scalia, não os autoriza a impor seu próprio ponto de vista na ausência de uma vontade democrática: "It is indeed true that later generations can see that laws once thought necessary and proper in fact serve only to oppress [...]; and when that happens, later generations can repeal those laws. But it is the premise of our system that those judgments are to be made by the people, and not imposed by a governing caste that knows best" 8

Outro argumento do Justice Scalia consiste em afirmar que a interdição da sodomia homossexual possui raízes antigas na história americana. Ela era considerada um crime na common law. Treze Estados condenavam essa prática no momento em que ratificavam a Bill of Rights. Em todos os casos em que há um grupo minoritário que demanda a aceitação de uma prática emergente, continua o Justice Scalia, tal prática não está, por definição, profundamente enraizada na história e na tradição da nação de modo a poder justificar um estatuto de "direito fundamental'. À questão de se existe um direito à conduta homossexual na Constituição americana, a resposta seria, para Scalia, simples: ninguém jamais pensou que quando a Bill of Rights foi adotada ela atribuía um direito à 


\section{8}

conduta homossexual. Essa conduta foi um delito por quase duzentos anos em todos os estados.

Como se pode verificar, o ponto central do voto minoritário envolve, primariamente, a questão da premissa majoritária segundo a qual o projeto político deliberativo dos diferentes estados é soberano em questões morais. Apenas direitos fundamentais profundamente enraizados na história e na tradição da nação estariam protegidos pelo heightened scruti$n y^{9}$. Argumentos históricos acerca da prática jurídica e social no momento onde a lei foi aprovada tornam-se, nessa perspectiva, fundamentais.

\section{Thomas Hobbes e o problema da interpretação da lei}

Será, a seguir, analisado o papel dos juízes em uma República ${ }^{10}$, segundo Thomas Hobbes, confrontado sua teoria com o que se denomina aqui, seguindo Ronald Dworkin, de "leitura originalista da Constituição" (Cf. DWORKIN. R. 1996, p. 12-15; DWORKIN. R. 1987), tal como pensamos ser a estratégia argumentativa do Justice Scalia no voto acima apresentado sucintamente. A questão posta no início desse texto é a seguinte: a Constituição norte-americana, em sua décima quarta emen$\mathrm{da}$, garante um direito à homossexualidade entre adultos e consentida?

Possuiria Hobbes uma teoria capaz de decidir o debate constitucional apresentado no caso Lawrence? Apesar do anacronismo da pergunta, creio que podemos, senão oferecer uma resposta peremptória, ao menos mostrar de que modo o filósofo de Malmesbury recusaria os argumentos do Justice Scalia como infundados e desprovidos de uma adequada compreensão das circunstâncias que envolvem a interpretação da lei civil. Como deveria um juiz, segundo Hobbes, decidir a controvérsia constitucional apresentada? É, necessário, naturalmente, que os juízes interpretem a lei. Mas de que modo?

2.1. Lei de natureza e lei civil em Thomas Hobbes: a função da soberania

Para situar a questão, é necessário, de início, recordar que a figura do soberano, em Hobbes, é instituída não apenas para assegurar a paz, inviável na ausência de um poder político, isso é, na circunstância onde 
os homens vivam em condição natural, mas também, e esse aspecto é fundamental, para fazer valer as leis de natureza, torná-las efetivas. Há um fundamento ético indissoluvelmente ligado à instituição do poder civil, e ele se encontra no necessário conhecimento das paixões que levam os homens a agir em vista de fins particulares. A ética, também denominada de filosofia moral, estabelece, em Hobbes, os primeiros princípios da política, pois nela estão contidos "os primeiros fundamentos dos deveres ou da doutrina civil, que é o coroamento da filosofia." (HOBBES, 1999, p. 17 e p. 77-78; HOBBES,1992, p. 87). ${ }^{11}$ A ciência dessas leis naturais, continua Hobbes no Leviatãa é a ética, "e a ética nada mais é do que a ciência das coisas que são boas ou más no comércio e na sociedade dos homens. (...) Desse modo, ninguém pode negar que os meios necessários à paz são bons. Ora, esses meios são a justiça, a gratidão, a modéstia, a eqüidade e todas as outras leis de natureza" (HOBBES, 2004, p.129-130). As leis de natureza, por sua vez, são tornadas efetivas através das leis civis estabelecidas pelo poder civil. Como é sabido, para Hobbes, na ausência de um poder comum capaz de submeter os homens e fazê-los renunciar à capacidade indiscriminada de usar dos meios que julguem necessários à manutenção de sua identidade, isso é, de sua vida, com vistas à aquisição de um bem aparente futuro, as leis de natureza permanecem como simples teoremas relativos aos meios que permitem a preservação da vida humana. Pois uma lei, no sentido próprio, é a palavra daquele ou daqueles que comandam (Cf. HOBBES, 2004, p. 130). O capítulo XXVI do Leviatã define do seguinte modo essa relação entre lei natural e lei civil:

"As leis de natureza e as leis civis contêm-se mutuamente. Toda lei de natureza, com efeito, é uma virtude moral: assim são a equidade, a justiça e a gratidão, que, como foi dito ao final do capítulo XV, não são leis propriamente ditas, mas qualidades. Elas são realmente leis, mas leis civis, quando a cidade comanda observá-las. As leis naturais são, portanto, também, leis civis" (HOBBES, 2004, p.206).

Ora, uma vez que o poder soberano foi instituído para dar efetividade às leis naturais, é a elas, portanto, que se deve voltar o legislador, como razão ou fundamento, no momento de criação das leis civis. A lei civil, por sua vez, enquanto comando, deve ser notificada, por oral, por escrito ou por 
outro sinal apropriado, àqueles a quem se destina. Além disso, ela deve ser interpretada. Assim, prossegue Hobbes:

"Uma vez conhecidas as leis e o legislador, resta ainda, se as leis devem ser obrigatórias, compreender sua verdadeira interpretação, na qual apenas consiste a essência da lei. Ora, pertence à mesma pessoa comandar e interpretar seus comandos, ordenar e explicar suas ordens. O único intérprete de todas as leis é, pois, o detentor do poder soberano ou aquele a quem foi dada autoridade nessa matéria."

A prerrogativa reivindicada pelo soberano de ser o único intérprete da lei civil é a condição mesma da paz. Evidentemente, todo cidadão pode interpretar a lei civil. Apenas a cidade pode interpretá-la definitivamente. «Uma vez a cidade (poder civil) instituída, a interpretação das leis naturais não depende dos doutores e dos escritores de filosofia moral, mas da autoridade da cidade (civil). Suas doutrinas podem ser verdadeiras, mas é a autoridade, e não a verdade, que faz a lei.» Permanece ainda o problema relativo à interpretação da lei, pois será de tal interpretação que dependerá a potência da República. Um soberano que não busca, por exemplo, em um litígio, tratar igualmente as partes, enfraquece sua potência, pois, ao cometer um ato hostil contra um ou alguns cidadãos, contraria a própria finalidade pública de sua instituição. A continuidade do poder político depende, pois, do respeito às leis de natureza, inscritas na cidade pela lei civil, e da efetivação do princípio mesmo da soberania, a salus populi. Da lei civil depende, portanto, a paz. Ora, continua Hobbes:

“Todas as leis, escritas ou não escritas, têm necessidade de interpretação. [...] Quanto às leis escritas, se são breves, a ambigüidade de uma ou duas palavras pode, todavia, torná-las obscuras. E se são longas, a ambigüidade de muitas palavras torna-as ainda mais obscuras. Por isso, toda lei escrita, que seja composta de muitas ou poucas palavras, apenas pode ser compreendida a partir das causas finais da lei ela mesma: ora, o conhecimento dessas causas pertence ao legislador apenas. Apenas ele pode resolver as dificuldade e os nós das leis, desatando-os ou resolvendo-os"(HOBBES, 2004, p. 210-11). ${ }^{12}$

Para Hobbes, a eqüidade e as leis constituem a razão e a vontade artificial da República.A unidade da cidade (civitas) reside na composição de todos 
os seus membros em torno de sua finalidade. Os magistrados, legisladores, conselheiros, etc., agem enquanto prepostos dessa vontade artificial da qual se investe o poder soberano. Tem-se aqui uma distinção fundamental entre a pessoa moral e a pessoa natural do soberano. Essa distinção é crucial, uma vez que se deve bem compreender que o princípio da soberania não repousa na vontade natural do soberano, mas na vontade que é a sua enquanto pessoa moral, isso é, enquanto representante da República.

Portanto, quando os magistrados se interrogam sobre a significação de expressões como "processo legal regular" ou "igual proteção das leis" presentes da décima quarta emenda da constituição americana, é a vontade pública do poder civil que eles devem interrogar. É preciso compreender que, em Hobbes, a interpretação da lei não é nem uma introspecção psicológica acerca daquilo que pensa o poder político, nem uma prospecção histórica, mas uma atividade estritamente jurídica e política.

Retomando, agora, a partir de uma perspectiva hobbesiana, a questão proposta no início desse artigo. Qual é a causa final de décima quarta emenda? Para responder a essa pergunta é preciso dirigir-se ao legislador. Mas quem é o legislador? Ele é, como foi explicado acima, o soberano. Mas, finalmente, quem é o soberano e qual é a sua vontade? Vejamos o que Hobbes tem a dizer sobre isso:

"A interpretação correta de não importa qual lei natural [e, acrescentaria aqui, de toda lei] é a sentença do detentor do poder supremo ou daquele a quem ele deu autoridade para conhecer tais causas. Esse último dá sua interpretação aplicando a lei ao fato. E essa interpretação é autêntica não porque é a sua sentença, mas porque é a da cidade" (HOBBES, 2004, p. 210).

A interpretação, portanto, é autêntica porque é dada pelo soberano em sua pessoa pública, isso é, enquanto representante da cidade. A intenção que é preciso buscar é, pois, a da civitas. Se lembrarmos agora que o soberano é instituído para fazer valer as leis de natureza, todo problema consistirá em saber qual decisão é a melhor para a conservação da República, para a preservação da paz civil. Nesse ponto, é necessário citar outra passagem de Hobbes que descreve o funcionamento da razão do juiz:"Assim, se ele [o soberano] institui um juiz, é preciso que esse preste atenção ao fato de que sua sentença deve estar de acordo com a razão de 


\section{2}

seu soberano: e essa, sendo sempre suposta coincidir com a eqüidade, ele está a ela limitado pela lei de natureza.” (HOBBES, 1968, p. 318).

A eqüidade de que nos fala Hobbes consiste, para alguém que decide um conflito, em tratar as partes com igualdade. Sem isso, destroem-se as arbitragens, os julgamentos e, conseqüentemente, a paz ela mesma. A eqüidade, nesse contexto, implica a imparcialidade no tratamento das partes em litígio. A eqüidade exige, pois, tratar a todos igualmente. Segundo ela, os juízes devem aplicar as leis igualmente a todos os cidadãos.

E porque razão é preciso recorrer ao princípio da imparcialidade para interpretar a décima quarta emenda? Seu caráter genérico exige, para a interpretação, um recurso, segundo Hobbes, às leis naturais enquanto apontando o fim a que se destinam todas as leis civis. Assim, afirma a referida emenda: Nenhum Estado privará uma pessoa de sua vida, de sua liberdade ou de seus bens sem o processo legal regular, nem recusará a todos que estejam sob sua jurisdição a igual proteção das leis. Essa formulação extremamente ampla exige que o juiz decida em função de um certo fim que a norma aponta.

O justice Scalia, por exemplo, invoca, de um lado, a história dos costumes do povo americano e, de outro, a intenção dos pais fundadores da Constituição. Segundo ele, a proibição da sodomia não está sujeita ao heightened scrutiny, uma vez que não implica em um "direito fundamental" submetido à cláusula do Due Process. Deve-se notar, continua Scalia, que a proibição dessa conduta tem raízes antigas. A sodomia era uma ofensa criminal sob o common law. Ela era interditada pelas leis dos treze primeiros Estados que ratificaram a Bill of Rights, e foi mantida por muitos Estados. O precedente Bowers, segundo Scalia, conclui que um suposto direito a engajar-se em sodomia homossexual não está enraizado na história e na tradição da Nação.

2.2. A critica à tradição enquanto fundamento da lei em Hobbes.

Não é, segundo Hobbes, na intenção do legislador histórico que se deve buscar o sentido da lei. A renúncia ao uso do direito natural e a correspondente outorga à pessoa civil do soberano do direito de distinguir entre o certo e o errado não repousa em um momento mítico ancestral de renúncia recíproca de todos ao uso do direito natural. O poder soberano se exerce no tempo presente, e é nesse tempo que a intenção da 
vontade pública deve ser perscrutada. A interpretação da lei civil é uma prerrogativa do poder soberano que se exerce sempre no tempo presente:

"Com efeito, o legislador não é aquele pela autoridade de quem as leis foram instituídas no começo, mas aquele pela autoridade de quem elas são mantidas. [...] essas leis, mesmo se elas são muito antigas, tiram sua força de lei não do costume, mas da vontade do poder supremo do momento"(HOBBES, 2004, p. 207). ${ }^{13}$

Os argumentos históricos do justice Scalia, ao contrário, não se apóiam, em definitivo, na ordem jurídica positiva. Eles tomam como apoio algo que está para além do texto: uma história, uma ancestralidade, um momento fundador e petrificador da interpretação.

Uma coisa é certa, a atividade do juiz não é oracular, isso é, ela não consiste em propor uma interpretação arbitrária da lei. Além disso, se a ancestralidade constituísse a autoridade, poderíamos, segundo Hobbes, produzir mil autoridades que se contradiriam umas às outras. A história, a razão privada e mesmo a arte do juiz são impotentes para estabelecer o sentido da lei. Para Hobbes, a história nada pode ensinar acerca dos fundamentos do direito, da justiça e da soberania ${ }^{14}$.

Como bem afirmou o Justice Kennedy, no caso Lawrence, o precedente Bowers deve ser revisto, pois gerações futuras podem compreender que interpretações pensadas outrora como necessárias e mesmo apropriadas podem, de fato, servir apenas para oprimir.

Sobre a mesma problemática de hipótese de revisão dos precedentes, escreve Hobbes:

"Mas como não há nenhum juiz, nem subordinado, nem supremo, que

não se engane alguma vez e não pronuncie uma sentença contrária à

equiidade, se o mesmo juiz reconhece a seguir seu erro por ocasião de

uma causa semelhante, ele se encontra obrigado a pronunciar uma sentença mais equânime" (HOBBES, 2004, p. 210).

Quanto à segunda parte do argumento do Justice Scalia que consiste em apoiar-se na intenção originária dos primeiros legisladores, também ela não encontra fundamento na República. Com efeito, reencontrar a intenção do legislador é algo bem diferente de interpretar o texto que é o produto da atividade legislativa. Quando Hobbes afirma que é preciso 


\section{4}

buscar o fim da lei e que esse consiste na vontade do soberano, não se deve compreender aqui, como ficou demonstrado, que é de sua vontade enquanto pessoa privada que se trata. A vontade do soberano é a vontade pública, a qual é preciso sempre interpretar em função de uma situação presente. Dito de outro modo, não se trata de procurar compreender a intenção do legislador à época em que o texto foi promulgado, mas, antes, o texto ele mesmo no contexto presente.

Somos governados pelo resultado da atividade legislativa, isso é, pelas leis que os legisladores criaram, e não pelas intenções que teriam sido as suas outrora.

O que importa é encontrar uma interpretação do texto conforme à vontade pública do poder civil existente. No caso Lawrence, devemos buscar uma interpretação da décima quarta emenda que empreste a maior força possível ao conjunto dos princípios constitucionais americanos. É preciso, pois, que os juízes se demandem qual decisão é a mais equiitativa, isso é, a mais conforme à igual consideração de todos. É possível sustentar que em uma constituição liberal, como é a dos Estados Unidos, apenas uma parte da população possui o direito ao respeito de sua vida privada e de sua intimidade?

${ }^{1}$ Lawrence v. Texas, 539 U.S. 558 (2003).

2 "1. Whether Petitioners' criminal convictions under the Texas "Homosexual Conduct" law which criminalizes sexual intimacy by same-sex couples, but not identical behavior by different-sex couples - violate the Fourteenth Amendment guarantee of equal protection of laws? "2. Whether Petitioners' criminal convictions for adult consensual sexual intimacy in the home violate their vital interests in liberty and privacy protected by the Due Process Clause of the Fourteenth Amendment?

${ }^{3} \mathrm{O}$ argumento dos recorrentes aqui é pela inconstitucionalidade da lei do Texas, uma vez que interditava a sodomia entre duplas do mesmo sexo, mas não entre parceiros heterossexuais. A lei, portanto, não garantia uma igual proteção aos apelantes. O texto da Section 1 da $14^{a}$ Emenda afirma: "All persons born or naturalized in the United States, and subject to the jurisdiction thereof, are citizens of the United States and of the State wherein they reside. No State shall make or enforce any law which shall abridge the privileges or immunities of citizens of the United States; nor shall any State deprive any person of life, liberty, or property, without due process of law; nor deny to any person within its jurisdiction the equal protection of the laws." Disponível em: http://www.archives.gov/national-archives-experience/charters/constitution_amendments_11-27.html, acesso em 21-07-2007. Convém lembrar que a interpretação 
dessa disposição da $14^{a}$ emenda à Constituição conheceu uma evolução na história constitucional americana. Ela correspondia, inicialmente, à idéia de "justo processo para os acusados", norma de alcance puramente processual. Com o tempo, entretanto, a cláusula toma uma significação material que acentua menos o processo e mais o direito em disputa, concernindo a questão mesma proposta. Essa regra permitiu à Suprema Corte proteger os indivíduos contra avanços dos poderes públicos, interpretada enquanto permitindo impor aos estados federados o respeito à Bill of Rights.

$4 \mathrm{O}$ direito à vida privada constitui um dos aspectos do due process of law da décima quarta emenda.

5 Na decisão Bowers, de 1986, a Corte Suprema recusou-se, por cinco votos contra quatro, a condenar a lei do Estado da Geórgia que criminalizava a sodomia. A decisão concentrou-se sobre a questão de saber se a Constituição norte-americana conferia um direito à sodomia homossexual. A resposta negativa da maioria fundava-se, na ocasião, na referência a diversos elementos históricos destinados a demonstrar que a proibição da sodomia entre dois homens possuía raízes antigas nos Estados Unidos. Voltarei adiante a esse argumento histórico à luz da teoria hobbesiana. Para uma exposição e análise do caso, ver a apresentação de STRECK, L. ao livro de TRIBE, L. \& DORF, 2007, p. XXVI-XXVII, nota 13.

6 "Our obligation is to define the liberty of all, not to mandate our own moral code." Planned Parenthood of Southeastern Pa. v. Casey, 505 U. S. 833, 850 (1992).

7 Cf. Lawrence v.Wade, 539 U.S. 558 (2003).

8 Cf. Lawrence v.Wade, 539 U.S. 558 (2003).

${ }^{9}$ A lei do estado do Texas que penaliza a homossexualidade consentida entre adultos, ao discriminar uma prática não fundada na história e no common law, sempre segundo Justice Scalia, não estaria protegida pelo heightened scrutiny que autoriza a revisão, pela Corte, de normas que produzem injustificadas discriminações no domínio de direitos fundamentais. Sobre o heightened scrutiny ver STONE et. al., 1996, p. 595-782 e 1031-1039.

10 O Leviatã inglês utiliza a expressão commonwealth para traduzir Respublica, do latim.

11 Para as citações, serão utilizadas as abreviações usuais.. De Corpore, por exemplo, corresponderá aos Elementa Philosophica Sectio Prima De Corpore. EW, e OL, equivalem, respectivamente, aos English Works e à Opera latina de Hobbes, editadas por Sir William Molesworth, entre 1839-45. Para o De Corpore latino, é utilizada a edição de Schuhmann, De Corpore. Elementorum Philosophiae Sectio Prima, edição crítica, notas, apêndices, índice e introdução de Karl Schuhmann, com a colaboração de Martine Pécharman, Paris,Vrin, 1999. O número da página citado corresponde a essa edição.

12 Essas três últimas citações buscam chamar a atenção sobre a necessidade de que a lei seja notificada e interpretada. Na obscuridade da lei, é preciso buscar sua causa final.

13 "Legum earum authoritas, etsi antiquissimae sint, vim Legum, non a Consuetudine, sed a voluntate Summae Potestatis praesentis habent."

${ }^{14}$ Sobre esse ponto, ver LISBOA,W. B. O direito, a moral e os limites da justiça: algumas dificuldades legadas pelos modernos. Em COPETTI et. al., 2005.

doispontos, Curitiba, São Carlos, vol. 6, n. 3 - especial, p.135-146, abril, 2009 


\section{Referências bibliográficas}

DWORKIN, R. 1987. The Bork Nomination. The New York Review of Books. New York, v. 34 e n. 13, p. 3-10.

DWORKIN, R. 1996. Freedom's Law: The moral reading of the American constitution. Cambridge: Harvard University Press.

COPPETTI, A.; STRECK, L. \& L., ROCHA, L. S. 2005. Constituição, Sistemas Sociais e Hermenêutica. Porto Alegre: Livraria do Advogado.

HOBBES, T. 1968. Leviathan. Ed. MacPherson. Harmondsworth. Baltimore: Penguin Books.

HOBBES, T. 1992. Elementa Philosophica Sectio Prima De Corpore: English Works. Londres: Routledge-Thoemmes Press.

HOBBES, T. 1999. Elementa Philosophica Sectio Prima De Corpore: Opera Latina. Paris:Vrin.

HOBBES, T. 2004. Léviathan latin. Traduzido e anotado por François Tricaud e Martine Pécharman. Paris:Vrin.

STONE, G. R.; SEIDMAN, L. M.; SUNSTEIN, C. R. \& TUSHNET, M.V. 1996. Constitutional Law. New York: Little, Brown and Company.

TRIBE, L. \& DORF, M. 2007. Hermenêutica Constitucional. Belo Horizonte: Del Rey. 